\title{
1,2,3-Triazole-Dithiocarbamate Hybrids, a Group of Novel Cell Active SIRT1 Inhibitors
}

\author{
Yi-Chao Zhenga Long-Zhen Wang ${ }^{a}$ Li-Jie Zhao ${ }^{a}$ Li-Juan Zhao ${ }^{a}$ Qian-Na Zhan ${ }^{\text {a }}$ \\ Jin-Lian Ma ${ }^{a}$ Bin Zhang ${ }^{b}$ Meng-Meng Wang ${ }^{a}$ Zhi-Ru Wang ${ }^{a}$ Jin-Feng Li ${ }^{a}$ \\ Ying Liu ${ }^{a}$ Zhe-Sheng Chen ${ }^{c}$ Dan-Dan Shena Xue-Qi Liu ${ }^{a}$ Meng Rena Wen-Lei Lva \\ Wen Zhao ${ }^{a}$ Ying-Chao Duan ${ }^{d}$ Hong-Min Liua \\ aKey Laboratory of Advanced Pharmaceutical Technology, Ministry of Education of China; Co- \\ innovation Center of Henan Province for New drug R \& D and Preclinical Safety; Institute of Drug \\ Discovery and Development, Zhengzhou University, Zhengzhou, China; 'Henan Cancer Hospital, \\ Zhengzhou University, Zhengzhou, China; 'College of Pharmacy and Health Sciences, St. John's \\ University, New York, NY, USA; dSchool of Pharmacy, Xinxiang Medical University, Xinxiang, China
}

\section{Key Words}

Inhibitor • SIRT1 • Cancer

\begin{abstract}
Background/Aims: Human SIRT1 is reported to be involved in tumorgenesis, mainly due to its modulating effect on p53 by deacetylation on lysine382. A large quantity of SIRT1 inhibitors was applied in chemotherapeutic study, but few of them were applied into clinical trials. Methods and Results: In the current study, a novel series of compounds with 1,4-bispiperazinecarbodithioic acid methyl esters scaffold were characterized to have inhibitory potency to SIRT1 by molecular docking and biochemical evaluation. Further cell level study revealed that one of the most potent SIRT1 inhibitors, compound 3a, is cell active. It can upregulate the amount of $\mathrm{p} 53$ by accumulating the K382 acetylation of $\mathrm{p} 53$, which lead to the stabilization of p53 in human gastric cancer cell line MGC-803 cells. Meanwhile, we also found compound 3a can inactivate SIRT2 in cells, which suggests the compound as a nonselective SIRT inhibitor. Conclusion: All these findings indicate that compound $3 \mathrm{a}$ is a potent, reversible and cell active SIRT1 inhibitor and deserves further investigation as an anticancer agent or a biological tool.

\section{Introduction}

As an important branch in epigenetics, histone modifications such as methylation, acetylation, and phosphorylation, modulate gene expression by regulating the chromatin structure around the specific gene promoter as well as the stability of the targeted protein.

Y.-C. Zheng and L.-Z. Wang contributed equally to this work.

Ying-Chao Duan

and Hong-Min Liu

KARGER
School of Pharmacy, Xinxiang Medical University, Xinxiang, Henan, 453003, (China); Co-innovation Center of Henan Province for New drug R \& D and Preclinical Safety; Institute of Drug Discovery and Development, Zhengzhou University, 100 Kexue Avenue, Zhengzhou, Henan 450001, (China); E-Mail liuhm@zzu.edu.cn 


\section{Cellular Physiology Cell Physiol Biochem 2016;38:185-193 \begin{tabular}{l|l|l} 
and BOI: 10.1159/000438620 20, 2016 & $\begin{array}{l}\text { C) 2016 The Author(s). Published by S. Karger AG, Basel } \\
\text { www.karger.com/cpb }\end{array}$
\end{tabular} \\ Zheng et al.: Triazole-Dithiocarbamate Based SIRT Inhibitor}

Histone deacetylase (HDAC), a group of the histone modification regulators, has been characterized into three families that work together to keep global histone acetylation patterns. Among them, sirtuins (HDAC III) are distinctly different from HDAC I and II, since they deacetylate substrates in an NAD-dependent manner [1-3].

Until now, 7 homologues of Sirtuin have been discovered in mammals, displaying various targets, cell functions and sub-cellular localizations [4]. Silent mating type information regulation 2 homolog 1 (SIRT1), the best characterized Sirtuin member in humans, shuttles between the nucleus and cytoplasm. Different location allows SIRT1 deacetylation not only of histone substrates but also of a large spectrum of transcription factors and cofactors, such as p53, STAT3, E2F1, DBC1, AROS, PTP1B, FOXO, c-Myc, Ku70, CBX8 and so on [1, 5-15]. The first discovered non-histone target of SIRT1, p53, was suggested to play a central role in SIRT1-mediated functions in tumorigenesis[16]. As reported, p53 can be deacetylated and destabilized by SIRT1 with a specificity for the C-terminal Lys382 residue of p53 in vitro and in vivo $[17,18]$. When the activity of SIRT was inhibited by inactivators, such as tenovin- 6 , p53 was activated and had the potential to decrease tumor growth [19]. The SIRT1 inhibitors were widely explored in various human cancers such as breast cancer, colon cancer, prostate cancer, chronic myelogenous leukemia, and lung cancer with anti-proliferation effects [11, 20-24]. Hence, SIRT1 was considered as a promising target for cancer therapy [25].

In this article, with the aid of molecular docking and biochemical evaluation, we found a group of 1,2,3-triazole-dithiocarbamate hybrids as potent SIRT1 inhibitors, which was initially identified as weak anticancer agents by our group [26]. Further biochemical assay indicates that the most potent SIRT1 inhibitor, compound 3a, can reversibly inhibit SIRT1 on a recombinant level. Cell level experiments suggest that compound 3a can promote p53 stability and upregulate its expression by inactivating the deacetylation of SIRT1 on p53 K382 residue. All these results demonstrate that compound 3a is a potent and reversible SIRT1 inhibitor and may deserve further development as a SIRT1 inhibitor for cancer treatment.

\section{Materials and Methods}

\section{Cells and Cell Viability Assay}

The human gastric carcinoma cell MGC-803 was supplied by the Cell Bank of Shanghai Institute of Cell Biology, Chinese Academy of Sciences. Cells were cultured in DMEM medium, which was supplemented with $10 \%$ FBS. Cells were cultured in an incubator with $5 \% \mathrm{CO}_{2}$ at $37^{\circ} \mathrm{C}$ with medium changes every 2 days.

The cell viability was determined by MTT assay according to the manufacturer's brochure. This assay measures dehydrogenase enzyme activity in metabolically active tumor cells, as reflected by the conversion of MTT to formazan, which is soluble in tissue culture medium and is detected by absorbance (A) at $570 \mathrm{~nm}$. The production of formazan is proportional to the number of living cells, with the intensity of the produced color serving as an indicator of cell viability. The data were analyzed with Graphpad 6.0.

\section{Molecular Docking}

The structure of the SIRT1 binding site was obtained from the RCSB Protein Data Bank (http://www. rcsb.org/pdb). Docking simulations were carried out in two stages using AutoDock Vina designed and implemented by Dr. Oleg Trott in the Molecular Graphics Lab at The Scripps Research Institute [27]. To run autodock, we used a searching grid extended over the selected target proteins; polar hydrogens were added to the ligand moieties. Kollman charges were assigned and atomic solvation parameters were added. Polar hydrogen charges of the Gasteiger-type were assigned and the nonpolar hydrogens were merged with the carbons and the internal degrees of freedom and torsions were set.

SIRT activity assay

The prokaryotic expression vector of truncated SIRT1(193-747AA) was constructed with SIRT1 cDNA from Prof Hou-Zao Chen (Institute of Basic Medical Sciences, Chinese Academy of Medical Sciences \& Peking Union Medical College). Then the SIRT1 recombinant was induced and purified in E.Coli Bl21(DE3) and NiNTA(Qiagen). The peptide substrate used in the screening model was synthesized according to p53 sequence; 


\section{Cellular Physiology Cell Physiol Biochem 2016;38:185-193

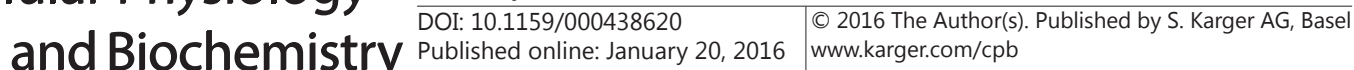 \\ Zheng et al.: Triazole-Dithiocarbamate Based SIRT Inhibitor}

it was comprised of $\varepsilon$-acetylated lysine and a conjoined 4-methyl-7-amide-coumarin moiety (AMC) at the carboxyl terminus of the RHKK sequence. The screening method contains two enzymatic catalysis reactions. Firstly, the peptide substrate is incubated with human recombinant SIRT1 along with its cofactor NAD+. Once the acetyl group is released form the peptide, the substrate can be recognized by trypsin in the second step, following by the release of the AMC fluorescence moiety. Finally, the free fluorophore can be detected using an excitation wavelength of $360 \mathrm{~nm}$ and an emission wavelength of $460 \mathrm{~nm}$. The reactions were suited to high-throughput screening, and the assay was performed in the 96-well microplate [28-30].

\section{Ultrafiltration and dialysis experiments}

The dialysis assay was done as published [31]. Briefly, $1.5 \mu \mathrm{g}$ of SIRT1 recombinant was incubated with $60 \mu \mathrm{M}$ compound 3a, $10 \mu \mathrm{M}$ EX-527, or DMSO for $30 \mathrm{~min}$. Then the mixtures were dialyzed against tris- $\mathrm{HCl}$ buffer at $4^{\circ} \mathrm{C}$ for $24 \mathrm{~h}$, and the buffer was refreshed each $24 \mathrm{~h}$. After dialysis, the SIRT1 activity was analyzed by the protocol mentioned above.

Before the ultrafiltration assay, the incubation of SIRT1 with compound 3a, EX-527 and DMSO were also done for $30 \mathrm{~min}$. A $10 \mathrm{kDa}$ ultrafilter was used to isolate SIRT1 from the mixture by using a refrigerated centrifuge at $4^{\circ} \mathrm{C}$ and $4000 \mathrm{xg}$. After each centrifuge, the effluent was aspirated. The buffer of the recombinant protein and compound were renewed.

\section{Western blotting}

Western blot was performed with the total lysates by RIPA or histone-purified with a kit from Epigentek. Equal amounts of cell lysates were denatured, separated by SDS-PAGE, and transferred to 0.2 $\mu \mathrm{m}$ nitrocellulose membranes. After blocking with PBS containing 5\% nonfat dry milk, the membranes were incubated overnight at $4{ }^{\circ} \mathrm{C}$ with primary antibody, followed by incubation with a horseradish peroxidaseconjugated secondary antibody. The immunoblots were visualized by enhanced chemiluminescence kit from Thermo Fisher. Antibodies used were against p53 (Santa Cruz no.sc-65334), Ac-p53(lys382) (CST, no.2525S), SIRT1(Abcam, no.ab12193), GAPDH(GoodHere no. AB-M-M 001), histone H4K16ac(Abcam, no.109463), H4(Abcam, no.10158), H3(Abcam, no.1791), Ac-alpha-tubulin(K40) (Abcam, No. ab179484), alpha-tubulin(Abcam, No. ab108629).

\section{Statistical Analyses}

Data were expressed as the mean \pm SD. The significance of the difference between different groups was determined with analysis of variance (ANOVA) and Student t-test. Results were considered statistically significant at $\mathrm{P}<0.05$. $\mathrm{P}<0.01$ was considered highly significant.

\section{Results}

Identification of compound 3 a as a potential SIRT1 inhibitor

In our previous report, we found a group of 1,2,3-triazole-dithiocarbamate hybrids as LSD1 inhibitors [31,32]. After that, we tried to optimized these compounds as a more potent LSD1 inhibitor, and a series of novel 1,4-bispiperazinecarbodithioic acid -methyl esters were synthesized and their anti-tumor activity were evaluated. Among them, compound 3a performed the most potent anti-proliferation activity in human gastric cancer cell line MGC803 with IC $50=11.15 \mu \mathrm{M}$. We further evaluated its LSD1 inhibitory effect by biochemical assay as published [31]. To our surprise, compound 3a performed no inhibitory effect against LSD1 recombinant. However, as compound 3a does not lose its anti-tumor effect completely, we hypothesize that it may target some other proteins that would lead to its anti-tumor activity. Using molecular docking (Fig. 1A), we found that compound 3a may penetrate into the active cavity formed by GLN300, ARG301, GLU246, ARG235 and GLN260 in SIRT1 and form three hydrogen bonds with two residues. As visualized in Fig. 1, one of the triazoles can form two hydrogen bonds with the -NH2 and -NH group of ARG235 at distance of $2.78 \AA$ and $2.284 \AA$, respectively. Additionally, the fluorine atom at the para-position of benzene ring can form a hydrogen bond with GLN300 at distance of $2.212 \AA$. All these hydrogen bond formation may lead to strong inhibitory effect of compound 3a against SIRT1. 


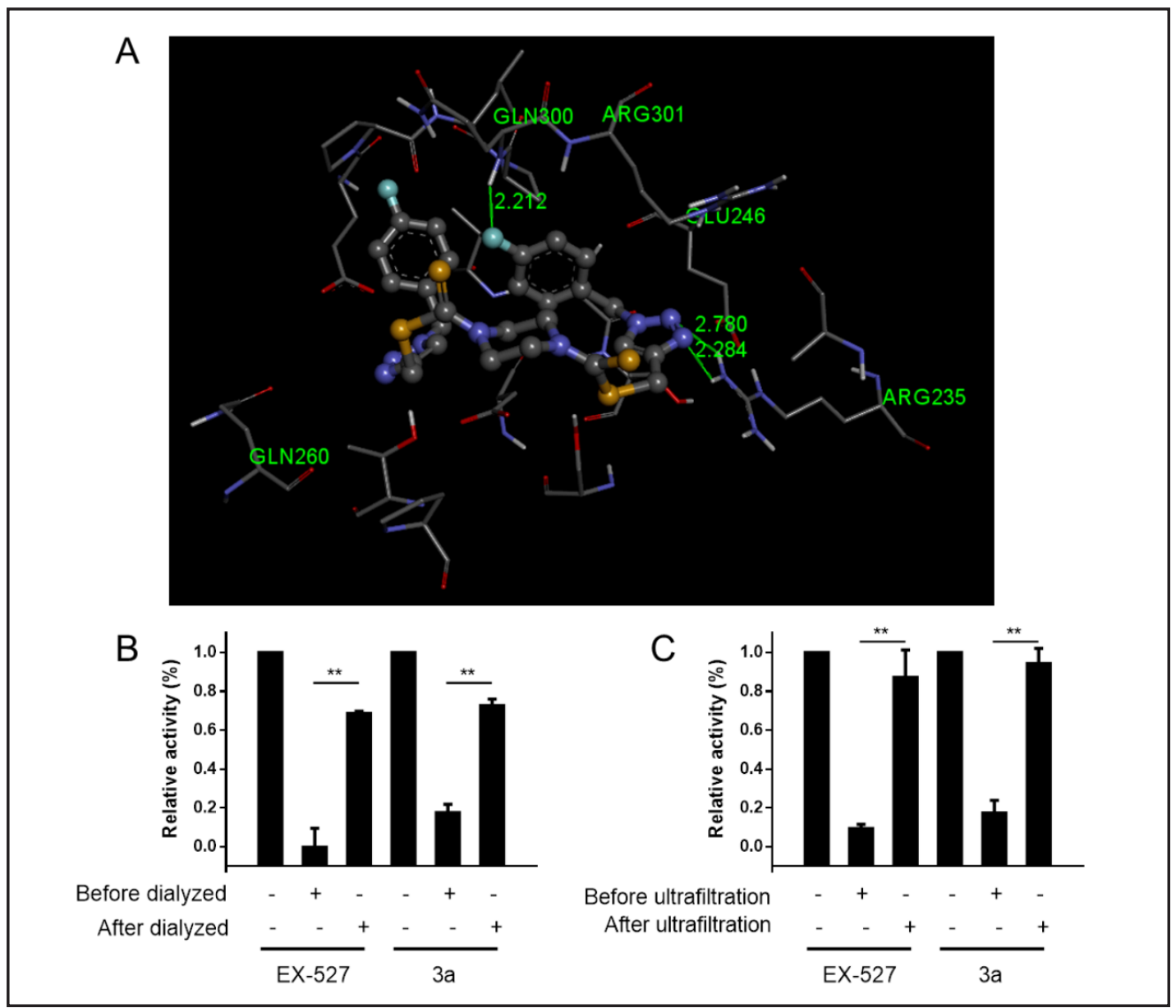

Fig. 1. Identification of compound 3a as a SIRT1 inhibitor. (A) Molecular docking of compound 3a with the published SIRT1 structure (PDB:4JT8); (B, C) The reversibility of compound 3a to SIRT1 activity was determined by dialysis experiment (B) and ultrafiltration assay (C). (**) $\mathrm{P}<0.01$ was considered statistically highly significant. All experiments were carried out at least three times.

Characterization of 1,2,3-triazole-dithiocarbamate hybrids as SIRT1 inhibitors

To further confirm our docking results, we evaluated the inhibitory effect of compound 3a against SIRT1 by biochemical assay. SIRT1 was recombined and purified from E.Coli, and fluorescence based SIRT1 inhibitor screening model was established using synthesized peptide Ac-His-Arg-Lys-Lys(Ac)-AMC as a substrate [33]. Consistent with our docking result, compound 3a can inhibit SIRT1 with IC50 $=1.08 \mu \mathrm{M}$, which indicated that compound 3a is a potent SIRT1 inhibitor. To further consolidate this group of 1,2,3-triazole-dithiocarbamate hybrids as SIRT1 inhibitors, all the previously published compounds were investigated for the inhibitory effect against SIRT1. As seen in Table 1, most of them demonstrated strong SIRT1 inhibitory effects.

The docking result visualized the three hydrogen bonds between SIRT1 and compound 3a, which insinuates the non-covalent binding between these two molecules. We hypothesized that their interaction is reversible, and to prove this, a reversible assay was investigated by dialysis experiment against Tris-HCl buffer after SIRT1 was inactivated by a high concentration of compound 3a. After dialysis, compound 3a was removed from the SIRT1/compound 3a mixture, and the activity of SIRT1 was restored, which supports the claim of reversible inhibition of compound $3 \mathrm{a}$, and indicates that compound 3a may inactivate SIRT1 by forming non-covalent bonds reversibly. Furthermore, an ultrafiltration experiment was also carried out to consolidate our result. $10 \mathrm{KDa}$ ultrafilter was used to

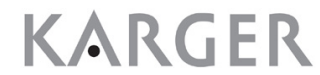


Table 1. Structures of compounds 3a30 and their inhibition rate (IC50) on the purified SIRT1 recombinant in vitro. The reagents and conditions for the synthesizing compounds 3a-3o were reported [32]. Data are represented as the mean \pm SD. All experiments were carried out at least three times

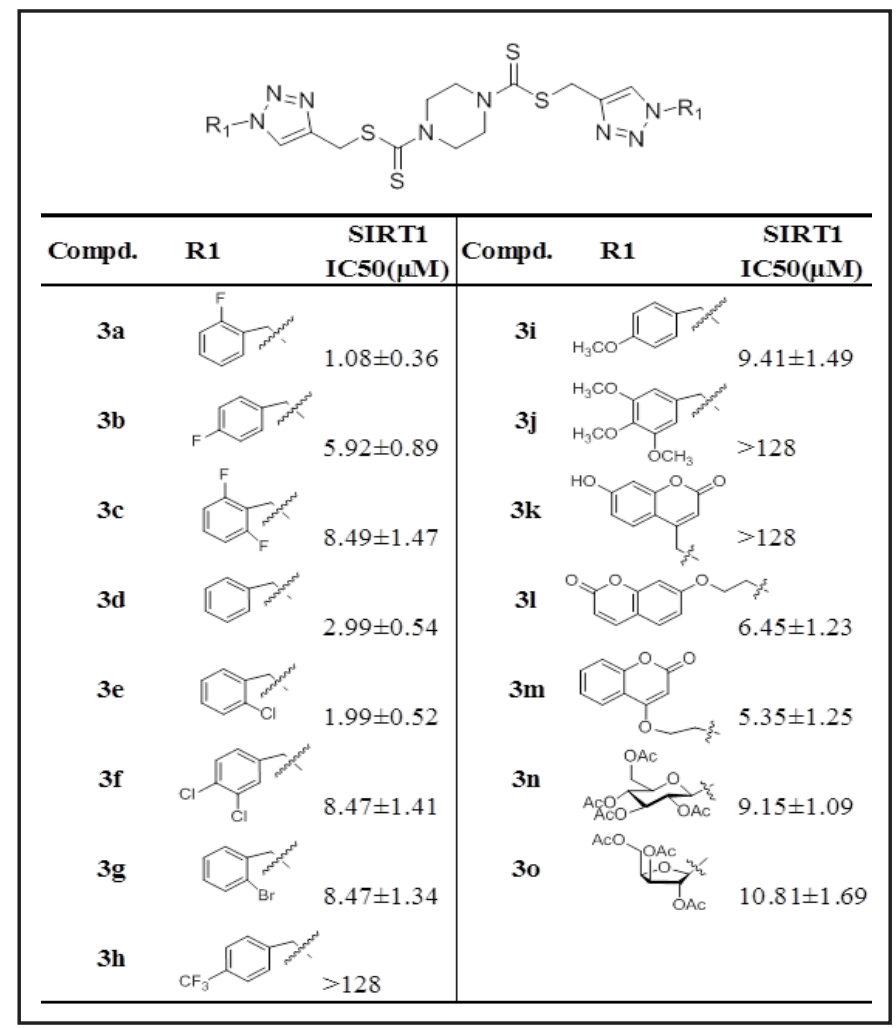

remove compound 3a after SIRT1 intermixed with compound 3 a for $30 \mathrm{~min}$ at $37^{\circ} \mathrm{C}$, and the activity of SIRT1 was evaluated before and after ultrafiltration. Similarly to the dialysis experiment, SIRT1 activity can also be recovered after ultrafiltration, which further supports the reversible inhibitory effect of compound 3a against SIRT1. The EX-527 was used as a control, which is reported to bind to SIRT1 through hydrogen bond and $\pi-\pi$ interaction [34].

\section{Inhibitory effect of compound 3a against SIRT1 and SIRT2 in cells}

As we have identified compound 3a as SIRT1 inhibitor on a recombinant level, we further evaluated its activity in cells. For this purpose, human gastric cancer cell line MGC-803 was chosen. Since the IC50 of compound 3a against SIRT1 is $1.08 \mu \mathrm{M}$ and the IC50 to inhibit MGC803 cells proliferation is $11.15 \mu \mathrm{M}$, we chose $5 \mu \mathrm{M}, 10 \mu \mathrm{M}$ and $15 \mu \mathrm{M}$ of compound 3a for the treatment of MGC-803 cells for $48 \mathrm{~h}$, and investigated the expression of p53, Ac-p53(Lys382) as the SIRT1 non-histone substrate and H4K16Ac as the SIRT1 histone substrate [16, 21, 35]. As presented in Fig. 2, the acetylation levels of SIRT1 substrates, p53 and H4K16, were concentration-dependently elevated after compound 3a treatment, which demonstrates the cellular activity of compound 3a against SIRT1.

SIRT2, homologous to SIRT1, was found to be located in the nucleus related to cell cycle regulation inside the cytoplasm. Several compounds targeting both SIRT1 and SIRT2 were described to have much stronger antitumor activity both in vitro and in vivo, and SIRT2 has been recognized as a tumor therapy target $[19,36]$. Hence, additional experiments to confirm the acetylation status of alpha-tubulin, a substrate of SIRT2, were also performed. We noticed that compound 3a promotes acetylation of alpha-tubulin K40 in a concentrationdependent manner either. In summary, we found that compound $3 \mathrm{a}$ acts as a nonselective SIRT1/SIRT2 inhibitor by increasing p53 acetylation at lysine 382, H4K16Ac and alphatubulin acetylation at lysine 40 .

As shown in Fig. 2, total p53 expression level was upregulated after treated with compound 3a. Frequent reports about activation of p53 by SIRT1 inhibitor can be found, but reports on more detailed mechanism are few [21,35]. As reported in literature, the expression level of p53 is mainly due to the interaction between MDM2 and p53 [37]. 


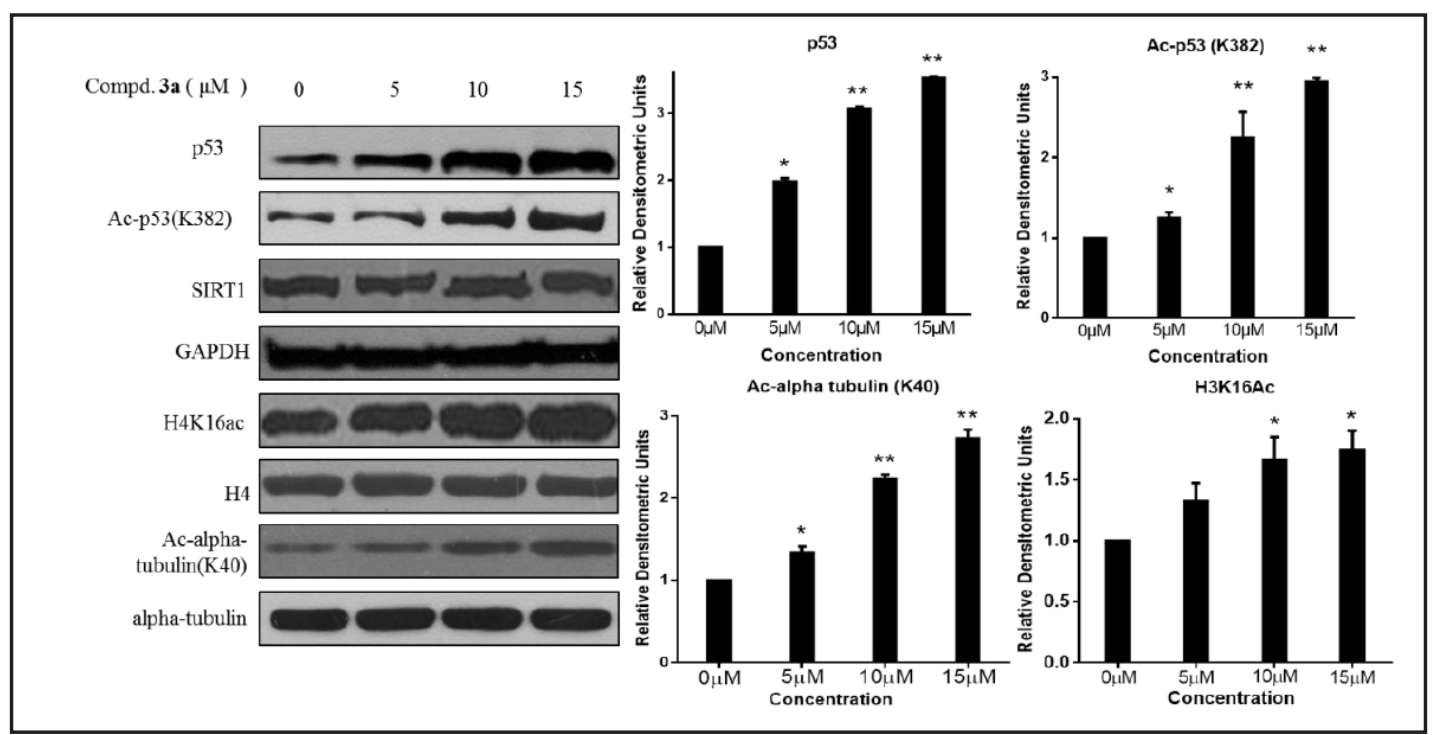

Fig. 2. The acetylation status of SIRT1 and SIRT2 substrates were determined by Western Blotting after 48h treatment with compound 3a. The expression of total p53, Ac-p53(K382), SIRT1, H4K16ac Ac-alphatublin(K40) were evaluated, GAPDH and total H4 were used as loading control. Data are represented as mean \pm SD,$\left({ }^{*}\right) \mathrm{P}<0.05$ was considered significant, $\left({ }^{* *}\right) \mathrm{P}<0.01$ was considered highly statistically significant. All experiments were carried out at least three times.

Fig. 3. Expression of p53 when the cells were treated with compound 3a singly and in combination with CHX as indicated. Data are represented as the mean \pm $\mathrm{SD},\left(^{*}\right) \mathrm{P}<0.05$ was considered significant, $\left({ }^{* *}\right) \mathrm{P}<$ 0.01 was considered highly statistically significant. All experiments were carried out at least three times.

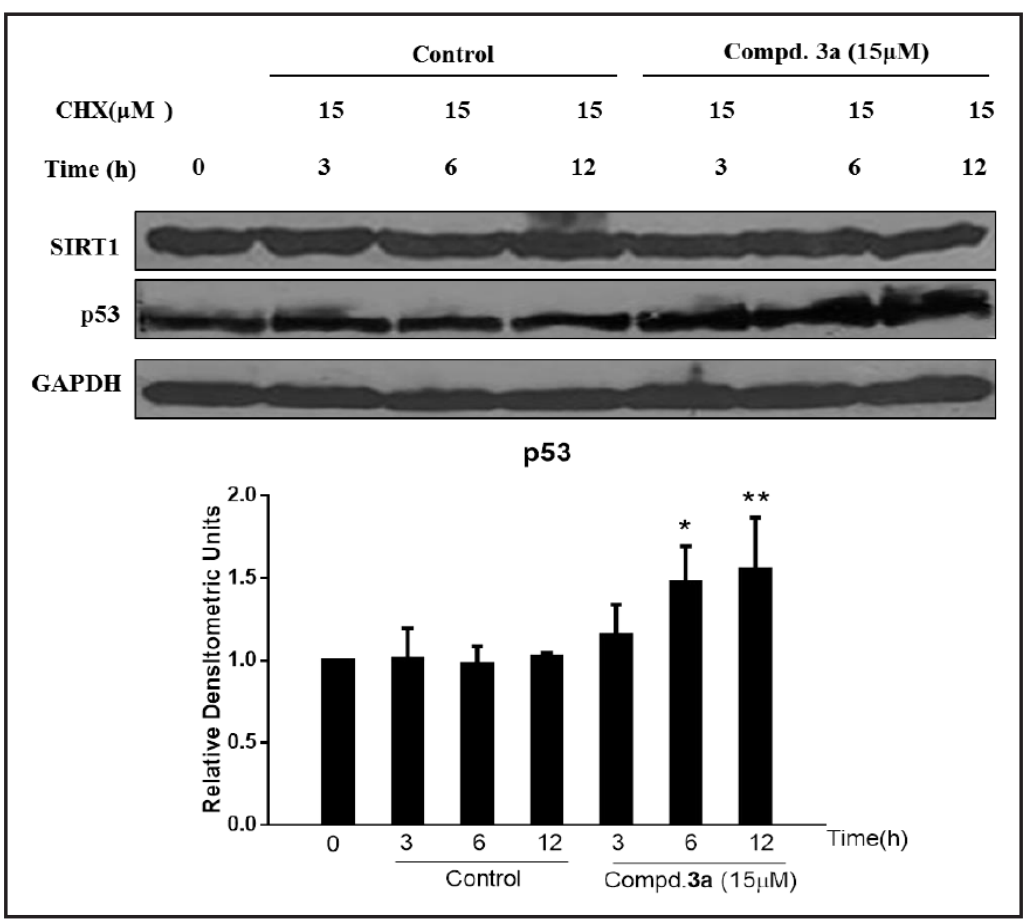

Therefore, an experiment to confirm that the upregulation of p53 is due to the decreased degradation at protein level instead of the accumulation of p53 mRNA was carried out by treating cells with compound 3a singly or in combination with cycloheximide (CHX). Two different groups, the control group and the group treated with compound $3 \mathrm{a}(15 \mu \mathrm{M})$, were exposed to $15 \mu \mathrm{M}$ CHX, and harvested at different time points. As seen in Fig. 3, there is no significant difference between the two groups for the expression of SIRT1, and neither of them changes the expression of SIRT1. Nevertheless, the expression of p53 was timedependently increased when the cells were treated with compound 3a in combination with 


\section{Cellular Physiology Cell Physiol Biochem 2016;38:185-193 \begin{tabular}{ll|l} 
DOI: 10.1159/000438620 & $\begin{array}{l}\text { O 2016 The Author(s). Published by S. Karger AG, Basel } \\
\text { www.karger.com/cpb }\end{array}$ \\
\hline
\end{tabular} \\ Zheng et al.: Triazole-Dithiocarbamate Based SIRT Inhibitor}

CHX, an inhibitor of protein biosynthesis in eukaryotic organisms, which indicated that the upregulation of p53 is due to the decreased degradation of p53. Based on these results, we can speculate that the SIRT1 inhibitor, compound 3a, can activate the expression of p53 by blocking the interaction of p53-MDM2, and enhance the stability of p53 at protein level.

\section{Discussion}

One concern should be taken into consideration is the IC50 of compound 3a, which is in micromolar range. There may be other possible targets of compound 3a. Actually, there are inhibitors of SIRT1 primarily found to be the p53 activators which are proved to inhibit SIRT1 $[19,21]$. We found that compound 3a can increase both total p53 and p53 acetylated level, so compound $3 \mathrm{a}$ is absolute a p53 activator as well. At the same time, SIRT1 inhibitors were reported to block DBC1, apoptotic signal cascades, and enhance androgen receptor expression. And we can find a wide variety of stuff like that, but whether they are the target of SIRT1 inhibitor is elusive, further research is needed to be done to clarify them.

As we have reported [31], another series of compounds based on 1,2,3-triazoledithiocarbamate hybrids structure have been proved to have inhibit potent aimed at LSD1, a lysine specific demethylase toward histone. Further research are undertaking in effort to discover novel compound targeted both LSD1 and SIRT1 so that the level of methylation and acetylation of histone can be both regulated.

\section{Conclusion}

A group of novel 1,2,3-triazole-dithiocarbamate hybrids were obtained in our initial experiment. With molecular docking and biochemical assay, most of them were characterized to inhibit SITR1 potently on recombinant level. On the cellular level, the most potent compound 3a stabilized p53 and promoted p53 expression as well as p53 K382Ac amount by targeting SIRT1, and also induced H4K16Ac accumulation. Furthermore, compound 3a inhibited SIRT2 on the cellular level, which led to the increasing amount of acetylation at alpha-tubulin K40. These compounds were further found to be cell active SIRT1 and SIRT2 inhibitors. As SIRT1 regulates a wide range of cellular and physiological processes, including cardiovascular diseases, type II diabetes, neurodegenerative diseases and cancer, while SIRT2 was proved to be useful in the treatment of neurodegenerative diseases and cancers [38-40], SIRT1 agonists were applied for aging related diseases, and its antagonists were considered as anti-cancer agents. In contrast, there is no agonist has been reported for SIRT2 toward any pathological processes [41]. In terms of cancer therapy, there are articles about predominant effect of non-selective inhibitors on both SIRT1 and SIRT2 [36, 42]. Compound 3a had promising anti-proliferative activity as well as SIRT1 inhibitory effect. As a result, compound 3a could be considered a starting point for the development of new SIRT1 inhibitors.

\section{Acknowledgements}

This work was supported by National Natural Science Foundation of China (Project No. 81430085, No. 21372206 and No. 81172937 for H.-M.L.; Project No. 81270270, No. 81470524 for W.Z.); Ph.D Educational Award from Ministry of Education (No. 20134101130001, for H.-M.L. and No. 20134101110013, for W.Z.); The 2013 Scientific Innovation Talent Award from Department of Education of Henan Province (No. 13HASTIT029, for W.Z.); The 2013 Young Teacher Foundation from Zhengzhou University (No. 000001307615, for Y.-C. Z.); Key Scientific Research Project for Higher Education by Department of Education of Henan Province, He'nan Educational Committee (No. 15A350018, for Y.-C. Z.). We thank Dr. Yangmin Chen (Medical Writer, Ross Clinical Research Organization, New Jersey) for editing the article. 


\section{Cellular Physiology Cell Physiol Biochem 2016;38:185-193

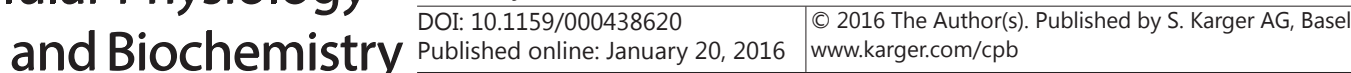 \\ Zheng et al.: Triazole-Dithiocarbamate Based SIRT Inhibitor}

\section{Disclosure Statement}

The authors declare no competing financial and any potential conflict of interest.

\section{References}

1 Kwon HS, Ott M: The ups and downs of SIRT1. Trends Biochem Sci 2008;33:517-525.

2 Marks P, Miller T, Richon M: Histone deacetylases. Curr Opin Pharmacol 2003;3:344-351.

3 Gallinari P, Di Marco S, Jones P, Pallaoro M, Steinkuhler C: HDACs, histone deacetylation and gene transcription: from molecular biology to cancer therapeutics. Cell Res 2007;17:195-211.

$4 \quad$ Feldman JL, Dittenhafer-Reed KE, Denu JM: Sirtuin catalysis and regulation. J Biol Chem 2012;287:4241942427.

5 Liu T, Liu PY, Marshall GM: The critical role of the class III histone deacetylase SIRT1 in cancer. Cancer Res 2009;69:1702-1705.

6 Canto C, Auwerx J: Targeting sirtuin 1 to improve metabolism: all you need is NAD(+)? Pharmacol Rev 2012;64:166-187.

7 Kalle AM, Mallika A, Badiger J, Alinakhi, Talukdar P, Sachchidanand: Inhibition of SIRT1 by a small molecule induces apoptosis in breast cancer cells. Biochem Biophys Res Commun 2010;401:13-19.

8 Escande C, Chini CC, Nin V, Dykhouse KM, Novak CM, Levine J, van Deursen J, Gores GJ, Chen J, Lou Z, Chini EN: Deleted in breast cancer-1 regulates SIRT1 activity and contributes to high-fat diet-induced liver steatosis in mice. J Clin Invest 2010;120:545-558.

9 Knight JR, Allison SJ, Milner J: Active regulator of SIRT1 is required for cancer cell survival but not for SIRT1 activity. Open Biol 2013;3:130130.

10 Sun C, Zhang F, Ge X, Yan T, Chen X, Shi X, Zhai Q: SIRT1 improves insulin sensitivity under insulin-resistant conditions by repressing PTP1B. Cell Metab 2007;6:307-319.

11 Lee SH, Um SJ, Kim EJ: CBX8 suppresses Sirtinol-induced premature senescence in human breast cancer cells via cooperation with SIRT1. Cancer Lett 2013;335:397-403.

12 Lou G, Liu Y, Wu S, Xue J, Yang F, Fu H, Zheng M, Chen Z: The p53/miR-34a/SIRT1 Positive Feedback Loop in Quercetin-Induced Apoptosis. Cell Physiol Biochem 2015;35:2192-2202.

13 Huang K, Yan ZQ, Zhao D, Chen SG, Gao LZ, Zhang P, Shen BR, Han HC, Qi YX, Jiang ZL: SIRT1 and FOXO Mediate Contractile Differentiation of Vascular Smooth Muscle Cells under Cyclic Stretch. Cell Physiol Biochem 2015;37:1817-1829.

14 Sin TK, Yung BY, Siu PM: Modulation of SIRT1-Foxo1 signaling axis by resveratrol: implications in skeletal muscle aging and insulin resistance. Cell Physiol Biochem 2015;35:541-552.

15 Ao N, Liu Y, Feng H, Bian X, Li Z, Gu B, Zhao X, Liu Y: Ubiquitin-specific peptidase USP22 negatively regulates the STAT signaling pathway by deubiquitinating SIRT1. Cell Physiol Biochem 2014;33:18631875.

16 Yi JJ, Luo JY: SIRT1 and p53, effect on cancer, senescence and beyond. Biochim Biophys Acta 2010;1804:1684-1689.

17 Vaziri H, Dessain SK, Eaton EN, Imai S-I, Frye RA, Pandita TK, Guarente L, Weinberg RA: hSIR2SIRT1 functions as an NAD-dependent p53 deacetylase. Cell 2001;107:149-159.

18 Langley E, Pearson M, Faretta M, Bauer UM, A.Frye R, Minucci S, Pelicci GP, Kouzarides T: Human SIR2 deacetylates p53 and antagonizes PML/p53-induced cellular senescence. EMBO J 2002;21:2383-2396.

19 Lain S, Hollick JJ, Campbell J, Staples OD, Higgins M, Aoubala M, McCarthy A, Appleyard V, Murray KE, Baker L, Thompson A, Mathers J, Holland SJ, Stark MJ, Pass G, Woods J, Lane DP, Westwood NJ: Discovery, in vivo activity, and mechanism of action of a small-molecule p53 activator. Cancer Cell 2008;13:454-463.

20 Yuan H, Su L, Chen WY: The emerging and diverse roles of sirtuins in cancer: a clinical perspective. Onco Targets Ther 2013;6:1399-1416.

21 Li L, Wang L, Li L, Wang Z, Ho Y, McDonald T, Holyoake TL, Chen W, Bhatia R: Activation of p53 by SIRT1 inhibition enhances elimination of CML leukemia stem cells in combination with imatinib. Cancer Cell 2012;21:266-281. 


\section{Cellular Physiology Cell Physiol Biochem 2016;38:185-193 \begin{tabular}{l|l|l|l|}
\hline DOI: 10.1159/000438620 2016 The Author(s). Published by S. Karger AG, Basel & $\begin{array}{l}\text { () 2016 Tiochemistry } \\
\text { www.karger.com/cpb }\end{array}$
\end{tabular} \\ Zheng et al.: Triazole-Dithiocarbamate Based SIRT Inhibitor}

22 Oh WK, Cho KB, Hien TT, Kim TH, Kim HS, Dao TT, Han HK, Kwon SM, Ahn SG, Yoon JH, Kim TH, Kim YG, Kang KW: Amurensin G, a potent natural SIRT1 inhibitor, rescues doxorubicin responsiveness via downregulation of multidrug resistance 1. Mol Pharmacol 2010;78:855-864.

23 Ruan Y, Dong C, Patel J, Duan C, Wang X, Wu X, Cao Y, Pu L, Lu D, Shen T, Li J: SIRT1 suppresses doxorubicininduced cardiotoxicity by regulating the oxidative stress and p38MAPK pathways. Cell Physiol Biochem 2015;35:1116-1124.

24 Nadal-Serrano M, Sastre-Serra J, Valle A, Roca P, Oliver J: Chronic-leptin attenuates Cisplatin cytotoxicity in MCF-7 breast cancer cell line. Cell Physiol Biochem 2015;36:221-232.

25 Cen Y: Sirtuins inhibitors: The approach to affinity and selectivity. Biochim Biophys Acta 2010;1804:16351644.

26 Wang MM, Duan YC, Ye XW, Ren JL, Yu B, Zhang E, Liu HM: Design, Synthesis and Antitumor Study of Novel 1,4-Bispiperazine-carbodithioic Acid [1-Substituted-(1,2,3-triazole)-4]-methyl Esters. Chin J Org Chem 2013;33:2384-2390.

27 Trott 0, Olson AJ: AutoDock Vina: improving the speed and accuracy of docking with a new scoring function, efficient optimization, and multithreading. J Comput Chem 2010;31:455-461.

28 Wegener D, Wirsching F, Riester D, Schwienhorst A: A Fluorogenic Histone Deacetylase Assay Well Suited for High-Throughput Activity Screening. Chem Biol 2003;10:61-68.

29 Wegener D, Hildmann C, Riester D, Schwienhorst A: Improved fluorogenic histone deacetylase assay for high-throughput-screening applications. Anal Biochem 2003;321:202-208.

30 Feng Y, Wu J, Chen L, Luo C, Shen X, Chen K, Jiang H, Liu D: A fluorometric assay of SIRT1 deacetylation activity through quantification of nicotinamide adenine dinucleotide. Anal Biochem 2009;395:205-210.

31 Zheng YC, Duan YC, Ma JL, Xu RM, Zi X, Lv WL, Wang MM, Ye XW, Zhu S, Mobley D, Zhu YY, Wang JW, Li JF, Wang ZR, Zhao W, Liu HM: Triazole-dithiocarbamate based selective lysine specific demethylase 1 (LSD1) inactivators inhibit gastric cancer cell growth, invasion, and migration. J Med Chem 2013;56:8543-8560.

32 Ye X-W, Zheng Y-C, Duan Y-C, Wang M-M, Yu B, Ren J-L, Ma J-L, Zhang E, Liu H-M: Synthesis and biological evaluation of coumarin-1,2,3-triazole-dithiocarbamate hybrids as potent LSD1 inhibitors. MedChemComm 2014;5:650-654.

33 Avalos JL, Bever KM, Wolberger C: Mechanism of sirtuin inhibition by nicotinamide: altering the NAD(+) cosubstrate specificity of a Sir2 enzyme. Mol Cell 2005;17:855-868.

34 Peck B, Chen CY, Ho KK, Di Fruscia P, Myatt SS, Coombes RC, Fuchter MJ, Hsiao CD, Lam EW: SIRT inhibitors induce cell death and p53 acetylation through targeting both SIRT1 and SIRT2. Mol Cancer Ther 2010;9:844-855.

35 Kim EJ, Kho JH, Kang MR, Um SJ: Active regulator of SIRT1 cooperates with SIRT1 and facilitates suppression of p53 activity. Mol Cell 2007;28:277-290.

36 Mahajan SS, Scian M, Sripathy S, Posakony J, Lao U, Loe TK, Leko V, Thalhofer A, Schuler AD, Bedalov A, Simon JA: Development of pyrazolone and isoxazol-5-one cambinol analogues as sirtuin inhibitors. J Med Chem 2014;57:3283-3294.

37 Zhao Y, Aguilar A, Bernard D, Wang S: Small-Molecule Inhibitors of the MDM2-p53 Protein-Protein Interaction (MDM2 Inhibitors) in Clinical Trials for Cancer Treatment. J Med Chem 2015;58:1038-1052.

38 Pillarisetti S: A Review of Sirt1 and Sirt1 Modulators in Cardiovascular and Metabolic .pdf. Recent Pat Cardiovasc Drug Discov 2008; 3:156-164.

39 Milne JC, Lambert PD, Schenk S, Carney DP, Smith JJ, Gagne DJ, Jin L, Boss O, Perni RB, Vu CB, Bemis JE, Xie R, Disch JS, Ng PY, Nunes JJ, Lynch AV, Yang H, Galonek H, Israelian K, Choy W, Iffland A, Lavu S, Medvedik O, Sinclair DA, Olefsky JM, Jirousek MR, Elliott PJ, Westphal CH: Small molecule activators of SIRT1 as therapeutics for the treatment of type 2 diabetes. Nature 2007;450:712-716.

40 Milne JC, Denu JM: The Sirtuin family: therapeutic targets to treat diseases of aging. Curr Opin Chem Biol 2008;12:11-17.

41 Mai A, Valente S, Meade S, Carafa V, Tardugno M, Nebbioso A, Galmozzi A, Mitro N, De Fabiani E, Altucci L, Kazantsev A: Study of 1,4-dihydropyridine structural scaffold: discovery of novel sirtuin activators and inhibitors. J Med Chem 2009;52:5496-5504.

42 Lara E, Mai A, Calvanese V, Altucci L, Lopez-Nieva P, Martinez-Chantar ML, Varela-Rey M, Rotili D, Nebbioso A, Ropero S, Montoya G, Oyarzabal J, Velasco S, Serrano M, Witt M, Villar-Garea A, Imhof A, Mato JM, Esteller M, Fraga MF: Salermide, a Sirtuin inhibitor with a strong cancer-specific proapoptotic effect. Oncogene 2009;28:781-791. 